\title{
CORRESPONDENCE
}

Sir: The councll must ensure that the College's work is pursued as its Charter requires.

It is difficult to see how this can be achieved if Members could 'pick and choose' which College activities their subscriptions should fund.

Perhaps the Welsh Division would see no need for the English Divisions, or the Child Psychiatrists dismiss the Section of Old Age!

It can further be argued that we are in a system that is fragmenting at the present time and that we can best maintain and even improve standards of psychiatric care through cohesion and collaboration.

F. CALDICOTT

The President, The Royal College of Psychiatrists

\section{Alice or Mrs Cooper?}

Sir: Hospital staff often approach elderly patients with an over-paternalistic and over-familiar attitude. They frequently assume - without consulting the patient - that he or she prefers to be addressed by his or her first name, rather than the family name. Many nurses and doctors believe that this promotes a warmer and more trusting interaction. However, the patient is not allowed to make the assumption that doctors prefer to be addressed by their first name. In fact, most elderly patients would never call the doctor by their christian name. This inequality reinforces the idea that the doctor-elderly patient relationship is the expression of the interaction between the powerful and the powerless. Nurses have more intimate contact with patients, an essential component of therapy, particularly in a psychiatric setting. However, it would be wrong for the nurse to assume that the patient favours a familiar treatment over a more formal one.

Previously, we found that those who use our psychogeriatric service prefer to be called patients rather than clients (Cybulska, 1994). We now report that $86 \%$ of 50 patients consulted in this unit, as well as in a local geriatric ward, prefer to be addressed by their christian or middle names while in hospital. Nurses in our services now ask the patient on admission how they would like to be called which is recorded in the notes. Familiarity is warm, but only when exercised with consent and equality, and not as a power statement.

CYBuLSKA. E. (1994) Patients, not clients - a community survey among elderly patients. Psychiatric Bulletin. 18. 509.

RAFAEL EUBA

Stone House Hospital, Cotton Lane, Dartford, Kent DA2 GAU

\section{Trainces, coffee rooms and missing notes}

Sir: I write to report two indirect consequences for trainees of the closure of larger psychiatric hospitals.

First, the emergence of smaller, geographically dispersed sites and subsequent shifts in medical resources and clinical commitments have signalled the death of 'coffee room psychiatry'. New units often lack a focal point for doctors, or geographical isolation prohibits attendance, meaning consultants and trainees have difficulty meeting for a relaxed lunch (if they still take lunchl), to discuss issues of the day away from the glare of formal case conferences and among sympathetic peers. This informal 'supervision' was often an integral lifeline to maintaining morale and good communication.

Second, dispersal of patient services has a similar effect on medical records and notes availability. Increasingly, community mental health teams hold notes locally, not centrally. This has implications for trainees who are increasingly being asked to formalise their research base (Owens et al, 1995).

For example, in Nottingham notes are now kept on two hospital sites but also at six community team bases. I attempted to review 1600 case notes as part of an MMedSci project. Apart from the expected attrition of some lost notes or those in use, $25 \%$ were unavallable since they were missing or at other sites, making review increasingly lengthy and difficult. Since retrospective case-control studies from case notes are often the 'bread and butter' of small research projects by trainees with limited research time, unavallable notes could provide significant feasibility and sample time problems and trainees need to be aware of this.

OWEns, D., House, A. \& WorRall, A. (1995) Rescarch by trainees. A strategy to improve standards of education and supervision. Psychiatric Bulletin. 19, 337-340.

JOHN MILTON

Nottingham Healthcare NHS Trust, Porchester Road, Nottingham NG3 6AA

\section{The last of the Victorian mental hospitals}

Sir: In the article by Cantwell \& Brewin on the Nottingham undergraduate curriculum (Psychiatric Bulletin August 1995, 19, 482-484) there is repeated, as an aside, the claim that Nottingham is the first major metropolitan area to close down its last Victorian mental hospital. In fact Liverpool closed its mental hospital, Rainhill, in 1991.

For a time some of the city's acute services were operated from a Victorian general hospital, Sefton 
General, but since March 1994 all acute services have been deltvered in the community or from small purpose-built general hospital units in the city. All that remains on the old Rainhill site is the Regional Secure Unit which was newly built as Rainhill was closing. All other specialised services have been reprovided within the city.

The population of Liverpool has shrunk somewhat but it would surely still rank as a "major metropolitan area'. Perhaps the lack of associated scandal or significant problems in the reprovision of services has led to Liverpool's achievement being overlooked?

M. W. FORTH

North Mersey Community Trust

\section{Increased Consultant job mobility - merit awards}

Sir: A matter has been raised at our meetings concerning the trend to increased consultant job mobility, which may have a detrimental affect upon a colleague's standing when being considered for $\mathbf{C}$ merit awards when changing jobs from one region or one part of the country to another. This may be particularly important with the proposed new arrangements, which will involve local representation and management, although hopefully there will still be room for College and other representation in the local arena.

We think it might be good policy for any consultant moving consultant appointments, particularly from one region to another, to send a copy of their curriculum vitae to the Chairman of their Division for this to be forwarded to the Chairman of the College Division of the region to which they are going. This would enable local College representation to continue to be made and prevent the individual concerned having to start earning a meritorious reputation all over again.

We are sure that there may be other lines of representation and would welcome colleagues' views on this matter, or even a College opinion.

C. E. HYDE

Public Education Officer for The Royal College of Psychiatrists, North West Division

\section{Was Jung a fraud?}

Sir: The press, both here (The Times, 5 June 1995) and in the United States, has made much of an attack on C. G. Jung in a book called The Jung Cult by one Richard Noll, a post-doctoral Fellow at Harvard. Noll accuses Jung of falsifying the details of a piece of evidence which Jung, and his followers, frequently cited in support of his theory of the collective unconscious. It concerned a schizophrenic patient who told Jung that if he stared at the sun with half-closed eyes he would see that the sun had a phallus and that this organ was the origin of the wind. Years later, so Jung said, he came across a Greek text describing an almost identical vision. The patient was a poorly educated man who could not have seen the text, even if he could have understood it, since it was published after his admission to hospital, where no such literature was available.

Noll's researchers have revealed certain discrepancies between Jung's oft repeated account and the facts. These are that the patient was not Jung's but one of Jung's assistants, J. J. Honneger, who two years after reporting the case committed suicide in 1911; the first edition of the book in which the Greek text appeared was published in 1903 (Jung's copy, published in 1910, was a second edition); earlier authors, such as Creuzer and Bachofen, had made references to the solar phallus before that date, and since these were published in German it is possible that the patient could have read them and they could have influenced the content of his hallucination. Noll castigates Jung for not making these facts known and for persisting with his original story, implying that this invalidates Jung's theory.

Although the Solar Phallus Man seems to have been Jung's favourite example to lllustrate his hypothesis of the collective unconscious, it has never seemed a particularly felicitous one. The hallucination is not readily explicable as the result of an archetype of the collective unconscious operating in different individuals living in different places at different times in history. Much more persuastve examples could have been given, such as the behaviour of generations of mothers and children as they work out their personal variations on the basis of the mother-child archetypal programme. To explain Jungs example it is necessary to postulate three archetypal objects (sun, phallus, and wind), an archetypal principle (that of masculine generativity) and an archetypal association between them (the sun's phallus generating the wind). Although such an association is statistically improbable, it is not impossible, but Jung could certainly have found a more persuasive example to support his theory.

In fact, the validity of Jung's hypothesis is in no way dependent upon the case of the Solar Phallus Man. It is striking how many workers in different fields have rediscovered the archetypal hypothesis and proposed it in their own terminology to explain their own observations. For example, the primary concern of Claude Levi-Strauss and the French school of structural anthropology is with the unconscious infrastructures which are held to be responsible for all human customs and institutions; specialists in linguistics maintain that although grammars differ from one another, their basic forms, which Noam Chomsky calls 